Our purpose was to characterize in the rhesus monkey the structure and function of vascularized temporalis muscle flaps innervated by the facial nerve after translocation into the site of the denervated zygomaticus muscle. Animals were killed at 28 to 120 days following translocation. Control data were obtained from the contralateral side. Twenty-eight days after translocation, the time to reach peak twitch tension and one-half relaxation time were $170 \%$ of control zygomaticus muscle. Contraction times decreased with time and reached control values by 100 days. Absolute isometric tetanic tension was not different between the flap $(4.29+1.28$ newtons; $X \pm S E M)$ and control zygomaticus ( $3.95 \pm 0.80$ newtons). Succinate oxidase activity of the flap decreased from $279 \pm 18 \mathrm{nl} \mathrm{O} / \mathrm{mg}$ protein/min to control zygomaticus values $(98 \pm 18)$ by 110 days. The type 1 fiber cross-sectional area of the flap was $52 \%$ of control temporalis muscle and $150 \%$ of control zygomaticus muscle $(P<0.05)$. The temporalis flap demonstrated viable structure and function and appeared useful in facial movements.

\title{
TRANSLOCATION OF THE TEMPORALIS MUSCLE FOR TREATMENT OF FACIAL PARALYSIS
}

TIMOTHY P. WHITE, PhD, JOHN A. FAULKNER, PhD,

JOHN M. MARKLEY, Jr., MD, and LEO C. MAXWELL, PhD

Clinical treatments for total or partial facial paralysis include static suspension or transposition of innervated and vascularized masseter or temporalis muscles. ${ }^{24} \mathrm{~A}$ static suspension provides support at rest but has no contractile function during pursing, chewing, or facial expression. Transposition of the masseter or temporalis muscle can provide some restoration of movement but has been criticized because of an unfavorable direction of action, a limited amount of shortening, and inappropriate movement due to innervation by the fifth rather than seventh cranial nerve. ${ }^{14,24}$

Freilinger ${ }^{10,11}$ reported a treatment for facial paralysis which involved translocation of a denervated central portion of the temporalis muscle into the site of the zygomaticus muscle. The temporalis flap was innervated by a cross-face nerve graft. The formerly paralyzed side of the face was functional 6 months later and electromyographic recordings were obtained from the transposed temporalis muscle. In human subjects the biological adaptations involved could not be quantified.

Using rhesus monkeys, we developed a model to study the skeletal muscle adaptations to the temporalis flap operation. We used ipsilateral reinnervation rather than a cross-face nerve graft since an additional 6 to 8 months experimental time was required for the nerve to regenerate the $17 \mathrm{~cm}$ distance across the snout prior to translocation surgery. Our purpose was to evaluate the structural and functional adaptations in vascularized temporalis flaps translocated into the site of the zygomaticus muscle and innervated by the ipsilateral seventh cranial nerve. We hypothesized that the structural and functional characteristics of the temporalis flap would change from those of the temporalis muscle and approach those of the zygomaticus muscle.

\section{MATERIALS AND METHODS}

Female rhesus monkeys (Macaca mulatta) were placed in quarantine in the Unit for Laboratory Animal Medicine. During quarantine they were screened for tuberculosis and other diseases. All

\footnotetext{
From the Department of Kinesiology (Dr. White), Department of Physiology (Drs. Faulkner and Maxwell), Department of Surgery, Section of Plastic Surgery (Dr. Markley), The University of Michigan, Ann Arbor, Ml.

Acknowledgments: Research supported by a United States Public Health Service Grant DE-04857 from the National Institute of Dental Research, Nationa! Institutes of Health. We acknowledge the technical assistance of Carol E. Brangwyn and Daniel M. Sosin.

Dr. Maxwell's current address is the Department of Physiology, University of Texas Health Science Center, 7703 Floyd Curl Drive, San Antonio, TX 75284 .

Address reprint requests to Dr. White at the Department of Kinesiology, The University of Michigan, Room 1273 CCRB, 401 Washtenaw Avenue, Ann Arbor, MI 48109

Received for publication January 29, 1982; revised manuscript accepted for publication May 21, 1982.

0148-639x/0507/0500 $\$ 01.25 / 0$

1982 John Wiley \& Sons, Inc
} 
tests were negative. Data are reported for 8 monkeys. Temporalis flap procedures were performed on one side of the face of each of 6 monkeys and the muscle on the other side served as a control muscle. Two monkeys had control muscles on both sides.

All operations were performed under sterile conditions. The monkeys were treated with procaine penicillin 1 day before and for 10 days after the operation. The animals were initially sedated with an intramuscular injection of ketamine hydrochloride $(10 \mathrm{mg} / \mathrm{kg}$ body weight) and then anesthetized with sodium pentobarbital (initially $10 \mathrm{mg} / \mathrm{kg}$ intravenously and supplemented as required).

At 28 to 56 days prior to the translocation surgery one zygomaticus major muscle was denervated by severing the facial nerve close to the muscle. The proximal nerve stump was sutured to the subcutaneous fascia in order to facilitate locating the nerve stump at the time of temporalis flap translocation.

To translocate the temporalis muscle flap, an incision was made to expose the entire temporalis muscle and the origin was detached from the cranium. The medial portion of the temporalis muscle served as the flap. Under an operating microscope (Zeiss OPMI-7, Carl Zeiss, Inc., New York, NY), the nerve branches to the flap were dissected back to the single motor nerve trunk which innervates the entire temporalis muscle. All branches to the flap were then excised for a length of 2 to $3 \mathrm{~cm}$ and the proximal stumps were electrocoagulated. Care was taken to maintain the nerves to the anterior and posterior portions and blood vessels to all portions. After denervation, two vertical cuts were made on either side of the central vascular supply to isolate the temporalis flap. The zygomatic arch was cut to allow greater freedom in translocation of the flap downward. The flap was then folded down over the zygomatic arch and tunneled subdermally to the corner of the mouth. The fascia of the flap was sutured to the subcutaneous fascia at the corner of the mouth. The previously severed seventh cranial nerve was implanted into a slit cut into the flap and anchored into the muscle with sutures. The anterior and posterior portions of the donor temporalis were sutured in their original sites, and the skin incisions were sutured closed.

The experimental monkeys were killed 28 to 120 days following translocation of the temporalis flap. The animals were anesthetized as described above and prepared for measurement of contrac- tile properties. ${ }^{9}$ The distal attachment of the temporalis flap or of the control zygomaticus muscle was freed, and the muscle was isolated to its origin. The blood flow and neural supply were left intact. A suture was placed in the distal portion of the flap for attachment of the muscle to a muscle lever. The monkey was placed in a supine position with the head extended backward and held securely with the zygomaticus muscle or the temporalis flap in a direct line of pull with a muscle lever. The muscle was set approximately at resting length, and two stainless steel needle electrodes were inserted in the proximal and distal portions of the muscle. Square-wave stimulation of $200 \mu$ sec duration was provided with a Grass model S48 stimulator (Grass Instrument Co., Quincy, MA). The voltage was adjusted to $110 \%$ of that which resulted in maximal isometric twitch tension. The muscle was then lengthened until an additional increase in length did not result in an increase in isometric twitch tension. This length was defined as resting length $\left(\mathrm{L}_{0}\right)$ and all subsequent contractions were initiated with the muscle initially at $\mathrm{L}_{0}$. We measured the maximum isometric twitch $\left(\mathrm{P}_{t}\right)$ and tetanic tension $\left(\mathrm{P}_{0}\right)$, time to reach peak twitch tension (TPT), and the time for half relaxation following $P_{t}(1 / 2 R T)$. The amount of shortening that occurred when a muscle contracted isotonically against a minimal afterload was also determined. Contractile properties were measured at muscle temperatures of $32 \pm 1 \mathrm{C}$. Contraction and relaxation times were adjusted, based on the relationship between these times and muscle fiber temperature, ${ }^{6,26}$ to values that would have been obtained at $37 \mathrm{C}$. The nomogram used for this adjustment is the inset in Figure 1.

Following the measurement of contractile properties, the muscles were excised and samples adjacent to each other were taken for measurements of oxidative capacity and for histochemical analyses. Oxidative capacity was measured by succinate oxidase activity determined with a Gilson differential respirometer ${ }^{23}$ (Gilson Medical Electronics, Middleton, WI). Muscle samples were weighed, minced with scissors and homogenized in 19 volumes of $10 \mathrm{mM}$ phosphate buffer $(\mathrm{pH}$ 7.4) using a Polytron homogenizer (Brinkman Instruments, Westbury, NY). Homogenate protein content was determined, ${ }^{20}$ and data were expressed as nanoliters of oxygen consumed per milligram protein per minute.

For histochemical analyses, samples were quick frozen in isopentane cooled with $\mathrm{CO}_{2}$. Crosssectional $14-\mu \mathrm{m}$ slices were cut from the frozen 
TIME TO PEAK TWITCH TENSION

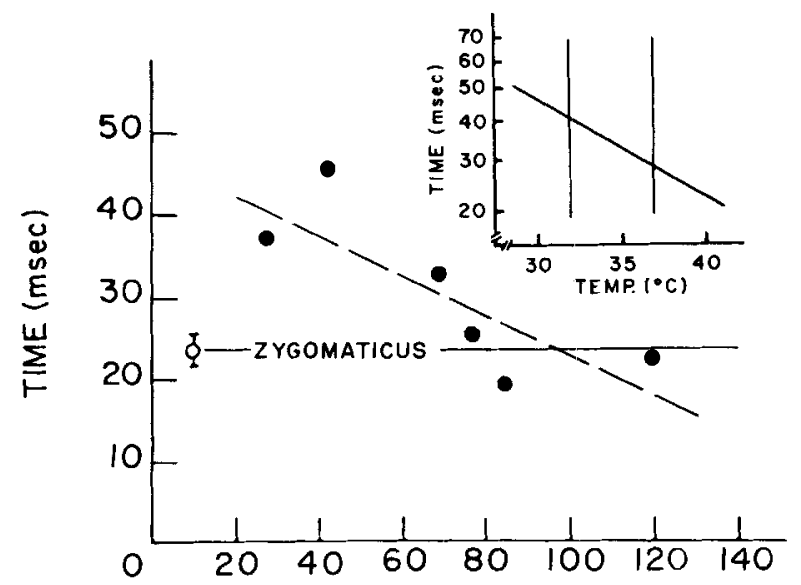

\section{DAYS FOLLOWING TRANSLOCATION}

Figure 1. Time to reach peak twitch tension of temporalis flaps plotted against the number of days following translocation. Each solid symbol represents data from one animal. The TPT of control zygomaticus muscle is indicated by the open symbol $(X \pm S E M ; N=3)$. Dashed line indicates linear regression for flap values $(y=-0.241 x+46.7 ; r=-0.80 ; P<0.05)$. Inset is the nomogram used to adjust contraction and relaxation times from 32 to $37 \mathrm{C}$. The time obtained is located on the $32 \mathrm{C}$ ordinate. Move paralle/ with the regression line to the $37 \mathrm{C}$ ordinate to obtain the adjusted time.

muscle on a cryostat (Ames Company, Elkhart, IN) and incubated for succinate dehydrogenase ${ }^{22}$ and myofibrillar ATPase ${ }^{4}$ activities ( $\mathrm{pH}$ 9.4). Based on these activities, fibers were classified using the nomenclature of Brooke and Kaiser. ${ }^{2}$ Fiber crosssectional area was determined by planimetry of muscle sections projected at $1,000 \times$ magnification.

All data are presented as mean \pm SEM. Linear regressions were performed to ascertain if the variables changed significantly with time following translocation. Statistical significance of differences between means was determined when appropriate by a modified $t$-test $(P<0.05$ accepted as significant). The $t$-tests were modified using the Welch-Aspin convention which does not require equal sample size and assumes variances to be unknown and not necessarily equal. ${ }^{21}$

\section{RESULTS}

Contraction and relaxation times and the oxidative capacity of whole muscle homogenates were the only variables which changed significantly with time following translocation. For all other variables, data were grouped prior to further analysis. Since no differences were observed between control data from experimental monkeys with contralateral control muscles and from monkeys which had bilateral control muscles, these data were grouped.

At 30 days following translocation, the TPT of the temporalis flap was $170 \%$ of the control zygomaticus muscle. The TPT decreased significantly with time and reached the control zygomaticus value by 100 days (Fig. 1). One-half RT demonstrated a similar relationship with time $(1 / 2 \mathrm{RT}$ [in $\mathrm{msec}]=-0.338$ [number of days] + 51.8; $r=-0.80 ; P<0.05)$ and reached control values for zygomaticus muscle $(17.0 \pm 0.5 \mathrm{msec})$ by 100 days. The TPT and $1 / 2$ RT data for control temporalis muscle could not be measured with the in situ technique used in this study. TPT $(22.4 \pm$ $1.1 \mathrm{msec})$ and $1 / 2 \mathrm{RT}(18.7 \pm 0.8 \mathrm{msec})$ of control temporalis muscles measured in vitro on small bundles of fibers were obtained from another study. ${ }^{8}$ The absolute tetanic tension $\left(\mathrm{P}_{0}\right)$ generated by the flap $(4.29 \pm 1.28$ newtons) was not significantly different from that generated by zygomaticus muscle ( $3.95 \pm 0.80$ newtons). During isotonic contractions with minimal afterload, the flap shortened to $83.0 \pm 4.5 \%$ of its resting muscle length. We have data on two control zygomaticus muscles which shortened to $57 \%$ of resting muscle length.

Succinate oxidase activity of control temporalis muscle was $279 \pm 18 \mathrm{nl} \mathrm{O} 2 / \mathrm{mg}$ protein $/ \mathrm{min}$. Over a period of 110 days, succinate oxidase activity of the flaps decreased to the control value for zygomaticus muscle, $98 \pm 18 \mathrm{nl} \mathrm{O} \mathrm{O}_{2} / \mathrm{mg}$ protein/ min (Fig. 2).

The type 1 fiber cross-sectional area of the temporalis flap was $52 \%$ of the value for control temporalis muscle and $150 \%$ of the value for control zygomaticus muscle $(P<0.05$; Table 1$)$. There were no differences in cross-sectional area of type $2 a$ and $2 b$ fibers between the flap, control temporalis and control zygomaticus muscles. The proportion of total fiber area of the flap represented by type 1 fibers was significantly less than values for control temporalis muscle and was greater than values for control zygomaticus muscle $(P<0.05$; Table 1). There were no differences in the proportion of total fiber area represented by type $2 \mathrm{a}$ fibers between the flap, control temporalis and control zygomaticus muscles. Compared to control zygomaticus, the proportion of area occupied by type $2 \mathrm{~b}$ fibers was lower in the flap and in control temporalis muscle.

\section{DIscussion}

The temporalis flap procedure provided a viable muscle mass that reinnervated and demonstrated a 


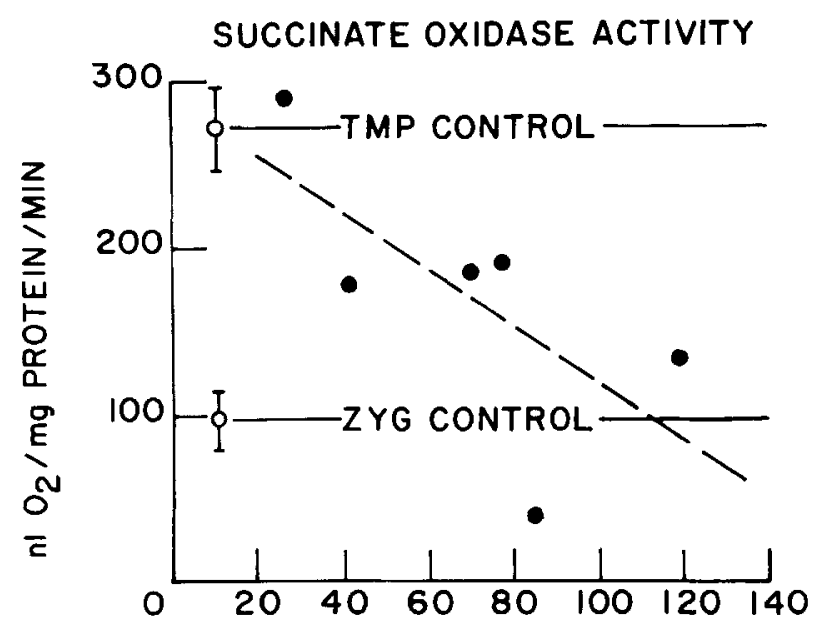

DAYS FOLLOWING TRANSLOCATION

Figure 2. Succinate oxidase activity of whole muscie homogenates of temporalis flaps plotted against the number of days following translocation. Each solid symbol represents data from one animal. Activity of control temporalis $(\mathrm{N}=7)$ and zygomaticus $(N=4)$ muscles are indicated by the open symbols $(X \pm S E M)$. Dashed line indicates linear regression for flap values $(y=-1.7 x+291.4 ; r=-0.68 ; P<0.05)$.

vigorous contractile response. Even 120 days following translocation, dissection of the temporalis flap revealed the flap as a separate entity with an intact muscle membrane. This differs from control zygomaticus muscle, which is composed of a thin sheet of fibers with both osseous and cutaneous attachments. ${ }^{27}$ Although the flap had structure and functional capabilities useful in facial movement, the flap was not integrated into the zygomaticus site.

Shortly after translocation, the TPT of the flap was significantly longer $(70 \%)$ than either control temporalis or zygomaticus muscles. Contraction times of denervated rat and cat skeletal muscles are $30 \%$ to $80 \%$ longer than control values. ${ }^{5,15,18}$ These data are consistent with the denervated condition of the flap at this time. Denervated skeletal muscles will become functionally reinnervated in approximately 40 days following implantation of a nerve. ${ }^{15.19,25}$ By 100 days, the TPT and $1 / 2$ RT of the flap were not different from control zygomaticus or temporalis muscles.

Since values for absolute $P_{0}$ were not different between temporalis flaps and control zygomaticus muscles, the flaps had the potential to develop equivalent forces during contractions involved in facial expression. The shortening to $57 \%$ of resting length shown by control zygomaticus muscle is in good agreement with data on parallel fibered muscles. ${ }^{12}$ Compared to control zygomaticus muscles, the impaired shortening ability of the flaps to $83 \%$ of resting length suggests that the fibers in the flaps were of shorter length and at a greater angle of pinnation. Therefore, in spite of the capacity of the temporalis flap to generate a maximum tension comparable to that of the zygomaticus muscle, its functional capabilities were different.

Oxidative capacity reflects the chronic activity pattern of muscle fibers. Oxidative capacity increases with endurance activity ${ }^{\mathbf{1 6}}$ and decreases with disuse. ${ }^{1}$ The initial decline in succinate oxidase activity of the flap following translocation may result from denervation. Following functional reinnervation oxidative capacity continued to decrease, and by 120 days following translocation was not different from that of control zygomaticus muscle (Fig. 2). These data are compatible with the premise that the temporalis flap, like the control zygomaticus muscle, had seventh nerve innervation and consequently both had similar habitual patterns of recruitment.

For control muscles, the mean area of type 1 fibers for the zygomaticus was $34 \%$ of the value for the temporalis muscle. The area of the type 1 fibers for the temporalis flap was intermediate between those of the control temporalis and zygomaticus muscles. Furthermore, large differences were observed between these two muscles in the pro-

Table 1. Mean fiber area and percentage composition by area of temporalis flap, control temporalis, and control zygomaticus muscles (values are mean \pm SEM).

\begin{tabular}{|c|c|c|c|c|c|c|}
\hline \multirow[b]{2}{*}{ Muscle } & \multicolumn{3}{|c|}{ Mean fiber area $\left(\mu \mathrm{m}^{2}\right)$} & \multicolumn{3}{|c|}{ Percentage composition } \\
\hline & Type 1 & Type $2 a$ & Type 2b & Type 1 & Type 2a & Type 2b \\
\hline $\begin{array}{l}\text { Temporalis flap } \\
(n=6)\end{array}$ & $1,477 \pm 215^{\star}+\dagger$ & $1,720 \pm 374$ & $1,881 \pm 440$ & $22.3 \pm 6.5^{\star *} \dagger$ & $47.4 \pm 8.7$ & $30.5 \pm 5.9 \dagger$ \\
\hline $\begin{array}{l}\text { Control temporalis } \\
\qquad(n=10)\end{array}$ & $2,842 \pm 186 \dagger$ & $1,613 \pm 116$ & $2,093 \pm 120$ & $49.8 \pm 6.6 \dagger$ & $31.4 \pm 4.8$ & $18.7 \pm 3.8 \dagger$ \\
\hline $\begin{array}{l}\text { Control zygomaticus } \\
(n=5)\end{array}$ & $980 \pm 167$ & $1,641 \pm 92$ & $2,328 \pm 141$ & $1.7 \pm 0.5$ & $28.5 \pm 8.6$ & $69.8 \pm 8.8$ \\
\hline
\end{tabular}

*Significantly different from control temporalis muscle $(\mathrm{P}<0,05)$.

$\dagger$ Significantly different from control zygomaticus muscle $(\mathrm{P}<0.05)$. 
portion of total cross-sectional area composed of type 1 and $2 b$ fibers, and the value for the flap was intermediate between those of the controls. Cross-reinnervation experiments have demonstrated the dependence of mammalian skeletal muscle fiber types on slow or fast motoneuron innervation. ${ }^{17,25}$ The changes observed in the histochemical characteristics of the temporalis flap are consistent with the change in innervation of the flap from the fifth cranial nerve to the seventh cranial nerve.

Burke et al. ${ }^{3}$ reported a strong correlation between histochemical classification of type 1 and 2 fibers and contractile properties. In developing ${ }^{13}$ and regenerating ${ }^{7}$ muscle, a high percentage of type 2 fibers was demonstrated, but the TPT and maximum velocity of shortening were slow. The present data on reinnervated fibers of the tem- poralis flap are in agreement with these latter studies. We noted a correlation $(r=0.50)$ between percentage type 2 area and 1/TPT which is not of physiological significance. The basis for the disparity between the histochemical data and contractile properties remains to be determined.

In summary, our data on the structure and function of temporalis flaps and control muscles of facial expression indicated that flaps could develop absolute isometric force equivalent to the control zygomaticus muscle, but the amount of shortening during isotonic contractions was less. The changes in oxidative capacity and muscle fiber characteristics of the flaps suggest modifications induced by the change from fifth to seventh cranial nerve innervation. The temporalis flap procedure resulted in a muscle mass which had viable structure and function and appeared useful in facial movements.

\section{REFERENCES}

1. Booth FW, Kelso JR: Gytochrome oxidase of skeletal muscle: Adaptive response to chronic disuse. Can J Physiol Pharmacol 51:679-681, 1973.

2. Brooke MH, Kaiser KK: Muscle fiber types: How many and what kind? Arch Neurol 23:369-379, 1970.

3. Burke RE, Levine DN, Zajac FE III, Tsairis P, Engel WK: Mammalian motor units: Physiological-histochemical correlates in three types in cat gastrocnemius. Science 174:709-712, 1971

4. Chayen J, Bitensky L, Butcher RG, Poulter LW: Practical Histochemistry. London, John Wiley \& Sons, 1973, pp 122124.

5. Dasse KA, Chase D, Burke D, Ullrick WC: Mechanical properties of tenotomized and denervated-tenotomized muscles. Am I Physiol 241(Cell Physiol 10):C150-C153, 1981 .

6. Faulkner, JA: Heat and contractile properties of skeletal muscle, in Horvath SM, Yousef MK (eds): Environmental Physiology: Aging, Heat and Altitude. Amsterdam, Elsevier/ North-Holland, 1981, pp 191-203.

7. Faulkner JA, Maxwell L.C, White TP, Niemeyer JH: Characteristics of autografted mammalian skeletal muscles, in Mauro A (ed): Muscle Regeneration. New York, Raven Press, 1979, pp 485-492.

8. Faulkner JA, McCully KK, Garlson DS, McNamara JA Jr: Contractile properties of the muscles of mastication of monkeys following an increase in muscle length. Arch Oral Biol, in press, 1982.

9. Faulkner JA, Niemeyer JH, Maxwell LC, White TP: Contractile properties of transplanted extensor digitorum longus muscles of cats. Am J Physiol 238(Cell Physiol 7):C120C. 126,1980 .

10. Fyeilinger $\mathrm{G}$ : A new technique to correct facial paralysis. Plast Reconstr Surg 56:44-48, 1975.

I I. Freilinger $G$; Dynamic reanimation for facial paralysis-a survey, in Freilinger G, Holle J, Carlson BM (eds): Muscle Transplantation. New York, Springer-Verlag, 1981, pp $135-143$

12. Gordon AM, Huxley AF, Julian FJ: The variation in isometric tension with sarcomere length in vertebrate muscle fibers. J Physiol (Lond) 184:170-192, 1966.

13. Guth L, Samaha FJ: Erroneous interpretations which may result from application of the "myofibrillar ATPase" his- tochemical procedure to developing muscle. Exp Neurol 34:465-475, 1972.

14. Hakelius L: Transplantation of free autogenous muscle in the treatment of facial paralysis. Scand J Plast Reconstr Surg $8: 220-230,1974$

15. Herbison GJ, Jaweed MM, Ditunno JF: Effect of activity and inactivity on reinnervating rat skeletal muscle contractility. Exp Neurol 70:498-506, 1980.

16. Holloszy JO, Booth FW: Biochemical adaptations to endurance exercise in muscle. Annu Rev Physiol 38:273-291, 1976.

17. Karpati G, Engel WK: Transformation of the histochemical profile of skeletal muscle by "foreign" innervation. Nature 215:1509-1510, 1967.

18. Kean CJC, Lewis DM, McGarrick JD: Dynamic properties of denervated fast and slow twitch muscle of the cat. $J$ Physiol (Lond) 237:103-113, 1974.

19. Kuno M, Miyata Y, Munoz-Martinez EJ: Properties of fast and slow alpha motoneurones following motor reinnervation. J Physiol (Lond) 242:273-288, 1974.

20. Lowry OH, Rosebrough WJ, Farr AL, Randall RS: Protein measurement with the folin phenol reagent. $J$ Biol Chem 193:265-275, 1951 .

21. Marascuilo LA: Statistical Methods for Behavioral Science Research. San Francisco, McGraw-Hill, 1971, pp 312-314.

22. Nachlas M, Tsou MK, deSouza E, Cheng C, Seligman AM: Cytochemical demonstration of succinic dehydrogenase by the use of new $p$-nitrophenyl substituted ditetrazole. $J$ Histochem Cytochem 5:420-436, 1957.

23. Potter VR: The homogenate technique, in Umbreit WW, Burris RH, Stauffer JF (eds): Manometric Techniques. Minneapolis, Burgess Publishing Co., 1964, pp 159-176.

24. Rees TD, Rhodes RD, Converse JM: Palliation of facial paresis. Am J Surg 120:82-88, 1970.

25. Romanul FCA, Van Der Meulen JP: Reversal of the enzyme profiles of muscle fibers in fast and slow muscles by cross-innervation. Nature 212:1369-1370, 1966.

26. Segal S, Faulkner JA: Static endurance of rat skeletal muscles at different temperatures in vitro. Med Sci Sports Exercise 14:106, 1982.

27. Swindler DR, Wood CD: An Atlas of Primate Gross Anatomy: Baboon, Chimpanzee and Man. Seattle, University of Washington Press, 1973, p 64. 